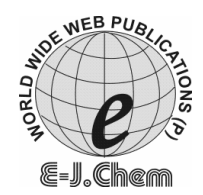

http://www.e-journals.net
ISSN: 0973-4945; CODEN ECJHAO

E-Journal of Chemistry

2010, 7(3), 1066-1070

\title{
Synthesis and Characterization of Substituted 4-Methoxy-1H-quinolin-2-ones
}

\author{
A.K.RAMASAMY, V.BALASUBRAMANIAM ${ }^{\S}$ and K. MOHAN* \\ Department of Chemistry, Periyar University, Salem, Tamilnadu, India. \\ ${ }^{\S}$ Department of Chemistry, Amet University, Chennai, India. \\ *Department of Chemistry, Sakthi Polytechnic College, Sakthinagar, 638315, India. \\ kmohanchitra01@gmail.com
}

Received 16 November 2009; Accepted 5 January 2010

\begin{abstract}
An efficient method for the synthesis of various substituted 4methoxy-1H-quinolin-2-ones from various substituted aniline with malonic acid, phosphorous oxychloride, sodium methoxide and glacial acetic acid under different conditions is described. The title compounds were synthesized from three steps; the first step involved the synthesis of substituted 2, 4-dichloro quinoline from aniline (substituted), with malonic acid and phosphorousoxychloride. In the second step, the substituted 2, 4 dichloro compounds was heated with freshly prepared methanolic sodium methoxide solution to give 2, 4-dimethoxy quinoline compounds, it was then refluxed with glacial acetic acid and hydrochloric acid to give the titled compounds in the final step. The purity of the synthesized compounds was confirmed by their $\mathrm{C}, \mathrm{H}$ and $\mathrm{N}$ analysis and the structure was analyzed on the basics of Mass, FT-IR and ${ }^{1} \mathrm{H}$ NMR.
\end{abstract}

Keywords: Substituted anilines, Synthesis, Quinolin-2-one, Phosphoryl chloride, Efficient method.

\section{Introduction}

Heterocyclic compounds have different types of pharmacological properties ${ }^{1-2}$. Several quinolones like ciprofloxacin, pefloxacin, levofloxacin, spafloxacin are released in the clinical world. Synthesis of various substituted quinolone intermediate compounds is of current interest because of their therapeutically potential in the area of human and animal health such as antibacterial ${ }^{3-5}$, antimicrobial ${ }^{6}$ and antituberculosis ${ }^{7-9}$ activities. Combe's et al. ${ }^{10}$ synthesized the 2,4-disubstituted quinolone.A reaction relates to Skarup and Doebner-Von Miller Synthesis was discovered by comb's in $1888 . \mathrm{He}$ condensed an aromatic amine with 1,3-diketone under acid condition to give 2, 4disubstituted quinolone.These biological data prompted us to synthesis some new substituted 4- methoxy- $1 H$-quinolin-2-ones.Earliar publications described the synthesis of substituted quinolone ${ }^{10-17}$, by cyclocondensation. 
The classical synthetic protocols for the quinoline intermediates and natural products suffer some of disadvantages such as low yield ${ }^{18}$, lack of easy availability/preparation of the reagent ${ }^{19-20}$ prolonged reaction time $(24 \mathrm{~h})$, multiple steps, requirement of excess of reagents/catalyst, need for special apparatus and harsh condition ${ }^{19}$. Hence we felt that it is worthwhile to synthesis a few substituted-4-methoxy- $1 H$ - quinoline-2-one compounds in a convenient, efficient approach, the structure and characterization of these compounds are confirmed by FT-IR, Mass and ${ }^{1} \mathrm{H}$ NMR.

\section{Experimental}

All the chemicals were purchased from Loba chemical. The reagents and solvents were analytical grade and were used without further purification unless otherwise mentioned. Carbon, hydrogen and nitrogen were determined by Perkin-Elmer 2400 instrument. All the melting points were taken in open in capillaries and were uncorrected. Chromatographic purifications were carried out Silica gel 60(230-400 mesh) and TLC (silica gel) was done on silica gel coated (Merck Kiesel 60 F 254, 0.2mm thickness) sheets.

Electronic absorbance spectra were recorded on a Varian Cary 5E UV-VIS spectrophotometer. Mass spectra were recorded at 70ev on a Joel JMS-D-300instument.IR Spectra were recorded as KBr pellet on a Perkin-Elmer-1700 Spectrophotometer ${ }^{1} \mathrm{H}$ NMR were recorded on $500 \mathrm{MHZ}$ Bruker FT-NMR spectrometer using tetra methyl silane as internal standard and the chemical shifts were reported in $\delta$ ppm units.

\section{General procedure for the synthesis}

Synthesis of substituted 2, 4-dichloro quinoline

An equimolar mixture of $(0.1 \mathrm{~m})$ aniline/substituted aniline (Ia: aniline $9.31 \mathrm{~g}$, Ib: p-touldine $10.716 \mathrm{~g}$, Ic: 2, 4-dimethyl-phenylamine $12.108 \mathrm{~g}$ ) and an equimolar volume of phosphoryl chloride $(60 \mathrm{~mL})$ were taken in a RB flask fitted with a double surface reflux condenser. An equimolar malonic acid $(10.420 \mathrm{~g})$ was added carefully and the mixture was heated at $150{ }^{\circ} \mathrm{C}$ for $5 \mathrm{~h}$. The reaction mixture was cooled, poured into ice with vigorous stirring, neutralized with sodium carbonate, filtered, dried and recrystallized from ethanol to afford the desired substituted 2,4-dichloro quinoline (IIa) product as yellow powdered in good yield. Column chromatography (95:5 hexane:EtOAc) yielded the pure dichloroquinoline as off-white needles $(6.8 \mathrm{~g}, 62 \%)$, m.p $66-67{ }^{0} \mathrm{C}$ (lit. $\left.{ }^{21} 66{ }^{0} \mathrm{C}\right) ; \mathrm{R}_{\mathrm{f}} 0.51$ (95:5 hexane:EtOAc).

\section{Synthesis of substituted 2, 4-dimethoxy quinoline}

The substituted 2, 4 dichloro compound (2.8 g, 14 mmol of IIa:2,4 Dichloroquinoline, IIb:2,4-dichloro-6-methyl-quinoline, IIc:2,4-dichloro-6,8-dimethyl-quinoline) was heated with freshly prepared methanolic sodium methoxide solution (from $2.0 \mathrm{~g}, 86 \mathrm{mmol} \mathrm{Na}$ in 50 $\mathrm{mL} \mathrm{MeOH}$ ) in water bath for $5 \mathrm{~h}$.The reaction mixture was cooled, the contents were poured into ice, neutralized with acetic acid, and the resulting white precipitate was filtered off. The compound 2, 4-dimethoxy quinoline (IIIa) was washed with water and recrystalized from methanol. Column chromatography (9:1hexane: EtOAc) yielded the 2, 4 dimethoxyquinoline, $(2.65 \mathrm{~g}, 62 \%)$ as white needles. M.p $78-80{ }^{\circ} \mathrm{C}$ (lit. $\left.{ }^{22} 81-82{ }^{\circ} \mathrm{C}\right)$.

Synthesis of substituted 4-methoxy-1H-quinolin-2-one

The substituted 2,4-dimethoxy quinoline (2.0 g, $11 \mathrm{mmol}$ of IIIa:2,4-dimethoxyquinoline, IIIb: 2,4-dimethoxy-6-methyl-quinoline, IIIc:2,4-dimethoxy-6,8-dimethyl-quinoline) was refluxed with glacial acetic acid and con. $\mathrm{HCl}$ in a R.B flask for $4 \mathrm{~h}$. The reaction mixture was 
concentrated and poured into the beaker containing crushed ice and neutralized with sodium carbonate. The compound was filtered, dried, purified by recrystallisation from hot ethanolwater and again chromotogrphed to yield the pure compound 4-methoxy- $1 \mathrm{H}$-quinolin-2-one (IVa) $(1.60 \mathrm{~g}, 60 \%)$, m.p. $\left.249-252{ }^{\circ} \mathrm{C} \mathrm{lit} .{ }^{23} 250-253{ }^{\circ} \mathrm{C}\right)$. The spectral and analytical data of the compound was confirmed the structure (Scheme 1).

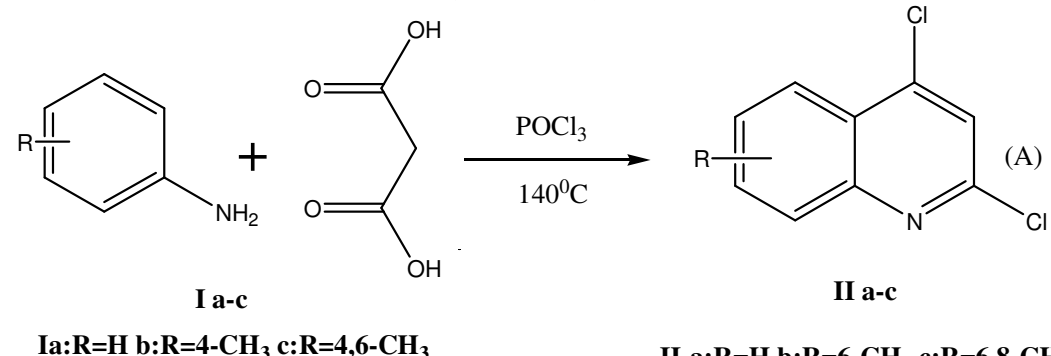<smiles></smiles>

IV a-c

IV-a:R=H b:R=6- $\mathrm{CH}_{3} \mathrm{c}: \mathrm{R}=6,8-\mathrm{CH}_{3}$

$$
\text { (1) }
$$


The 4-methoxy -1H-quinolin-2-one solid showed absorption bands at $1600 \mathrm{~cm}^{-1}$, $3000-3300 \mathrm{~cm}^{-1}, 2950-2853$ (CH-Stretch), 800-700 (CH-bend), 1250 (-C-O-C Stretch), 880 (-C-N-Stretch) attributable to 2-quinolone and $\mathrm{NH}$ stretching vibrations. The ${ }^{1} \mathrm{H}$ NMR spectrum represented a doublet at $\delta 7.20$ for the $\mathrm{C}_{6}-\mathrm{H}$ protons, singlet at $\delta 6.21$ for the $\mathrm{C}_{3}-\mathrm{H}$, multiplet in the region $\delta 6.98-7.41$ for $\mathrm{C}_{7} \& \mathrm{C}_{8}$ aromatic protons, a singlet at $\delta 7.95$ for $\mathrm{C}_{5}-\mathrm{H}$ proton and a singlet at $\delta 3.99$ for $\mathrm{C}_{4}-\mathrm{OCH}_{3}$. Elemental analysis corroborated the proposed molecular formula: $\mathrm{C}_{10} \mathrm{H}_{9} \mathrm{NO}_{2}$.

Exactmass:175.063, mol.wt.:175.184, Found: C, 68.56; H, 5.40; N, 6.82; O, 7.79; S, 15.62. Calculated: C, 64.36, H, 5.18 and N, 8.00. Moreover the m.p of the solid is consistent with the literature ${ }^{24}$ value of 4 -methoxy- $1 H$-quinolin-2-one is $251{ }^{0} \mathrm{C}$. The spectroscopic properties of our synthetic material IIa, IIIa, \& IVa agreed well with those reported in literature ${ }^{24}$.

\section{4-Methoxy-6-methyl-1H-quinolin-2-one (IVb)}

$\nu_{\max }(\mathrm{KBr}) / \mathrm{cm}^{-1}: 3150(\mathrm{w}, \mathrm{N}-\mathrm{H}), 1680(\mathrm{~S}, \mathrm{C}=\mathrm{O}), 1635,1608(\mathrm{~S}, \mathrm{C}=\mathrm{C}) ; 1514$ (amide 11); ${ }^{1} \mathrm{H}$ NMR $\delta$ (ppm): 2.42 (s, 3H, C $\left.6-\mathrm{CH}_{3}\right), 3.98\left(\mathrm{~s}, 3 \mathrm{H}, \mathrm{C}_{4}-\mathrm{OCH}_{3}\right), 10.33$ (s, 1H,-NH), 6.02 (s, $\left.1 \mathrm{H}, \mathrm{C}_{3}-\mathrm{H}\right), 7.20-7.62\left(2 \mathrm{~d}, 2 \mathrm{H}, \mathrm{C}_{7}-\mathrm{H} \& \mathrm{C}_{8}-\mathrm{H}\right), 7.90$ (s, 1H, $\left.\mathrm{C}_{5}-\mathrm{H}\right)$; Anal.Found; C, 69.81; H, 5.88, N, 7.43; Calcd.for $\mathrm{C}_{11} \mathrm{H}_{11} \mathrm{NO}_{2} ; \mathrm{C}, 69.83 ; \mathrm{H}, 5.86 ; \mathrm{N}, 7.40 ; \mathrm{MS}(\mathrm{m} / \mathrm{z}): 189\left(\mathrm{M}^{+}\right)$.

\section{4-Methoxy-6,8-dimethyl-1H-quinolin-2-one (IVc)}

$v_{\max }(\mathrm{KBr}) / \mathrm{cm}^{-1}: 3300-3100(\mathrm{w}, \mathrm{NH}), 1674$ (s, C=O), 1630, 1608 (s, C=C); 1515 (amide 11); ${ }^{1} \mathrm{H}$ NMR $\delta(\mathrm{ppm}): 2.42\left(\mathrm{~s}, 3 \mathrm{H}, \mathrm{C}_{6} \mathrm{CH}_{3}\right), 3.98\left(\mathrm{~s}, 3 \mathrm{H}, \mathrm{C}_{4}-\mathrm{OCH}_{3}\right), 10.33(\mathrm{~s}, 1 \mathrm{H},-\mathrm{NH}), 6.02\left(\mathrm{~s}, 1 \mathrm{H}, \mathrm{C}_{3} \mathrm{H}\right)$, $7.62\left(\mathrm{~s}, 1 \mathrm{H}, \mathrm{C}_{7}-\mathrm{H}\right), 2.40\left(\mathrm{~s}, 3 \mathrm{H}, \mathrm{C}_{8}-\mathrm{CH}_{3}\right), 7.92\left(\mathrm{~s}, 1 \mathrm{H},-\mathrm{C}_{5} \mathrm{H}\right)$; Anal. Found; C, 70.90; H, 6.44, N, 7.95; Calcd. for $\mathrm{C}_{12} \mathrm{H}_{13} \mathrm{NO}_{2} ; \mathrm{C}, 70.92 ; \mathrm{H}, 6.45 ; \mathrm{N}, 6.89 ; \mathrm{MS}(\mathrm{m} / \mathrm{z}): 203\left(\mathrm{M}^{+}\right)$.

\section{Conclusion}

In summary we have clarified the synthesis of substituted 4-methoxy-1H-quinolin-2-one. The advantage of this new approach is that the reaction procedure is convenient, involves simple experimental procedure and the product isolation is easy. Hence it is the useful modification to the existing method. The reaction is carried out without using any catalyst. The reaction time is short, operable on a large scale. Work up is simple and the yields are excellent

\section{Acknowledgment}

The authors would like to thank the Sophisticated Analytical instrument Facility, Indian institutes of technology, Chennai for recording NMR, UV, Bharathiar University, Coimbatore for recording IR spectra and Periyar University for providing necessary facilities.

\section{References}

1. Kalsow and Marsh, J Org Chem., 1947, 12, 456.

2. Ukrainets I V, Taran S G, Gorokhova O V and Marusenko N A, Chem Heterocycl Compds., , 1997, 33, 600

3. Harrison E A Jr, Rice K C and Rogers M E, J Heterocycl Chem., 1977, 14, 909.

4. Mitsos C A, Zografos and Igglessi-Markopoulou J Org Chem., 2003, 68, 4567.

5. Narsinh D S and Anamik, Indian J Heterocyclic Chem., 2000, 10, 69.

6. Patel N B, Patel A L and Chauhan H I, Indian J Chem., 2007, 46B, 126-134.

7. World Health Organisation, Tuberculosis Fact Sheet, No, 104, 2006,

8. Nayayar A, Malde A, Coutinho E and Jain R, Bioorg Med Chem., 2006, 14, 7302. 
9. Miguel A Campos, Pau Morey and Jose A Bengoechea, Antimicrob Agents Chemother., 2006, 2361-2367.

10. Combes A.Bull Soc Chim France, 1888, 49, 89.

11. Patel N C and Mehta A, J Indian Council Chem, 2001, 18, 59.

12. Mukisumi and Murabayashi, Tetrahedron Letts., 1969, 2449; ibid, 1971, 2453.

13. Baur L and Gardella LA, J Org Chem., 1963, 28, 1320.

14. Nadaraj V S, Tamarai S S and Raju S, ARKIVOC, 2006, 82,

15. Arya K and Agarwal M, Bioorg Med Chem Lett., 2007, 17, 86.

16. Shanmugam P, Soundararajan N and Gnansekaran A, J Chem Soc Perkin 1, 1977, 2024; Coppolla G M, J Hetrocycl Chem., 1983, 20, 1217.

17. Srorer R and Young D W, Tetrahedron, 1973, 29, 1215.

18. Manandhar M D, Hussaini F A, Dapil R S and Shob A, Phytochem., 1985, 24, 199

19. Bhudevi B, Venkata Ramana P, Anwita Mudiraj and Ram Reddy A, Indian J Chem., 2009, 48B, 255-260.

20. Vidya D G, Jyothi B, Santhosh G T and Ragho S M, J Chem. Res(s)., 2003, 10, 628.

21. Osborne A G, Buely J M, Clarke H, Darkin R C H and Price P I, J Chem Soc Perkin Trans 1, 1993, 2747-2754.

22. Osborne A G and Warmsley J F, J Nat Prod., 1992, 55, 589-595.

23. Nickisch K, lose W K, NordhoffE and Bohlmann F, Chem Ber., 1980, 113, 3086-3088.

24. Keith Jones, Xavier Roset, Sharon Rossiter and Philip Whittiels, Org Biomol Chem., 2003, 1, 4380-4383. 


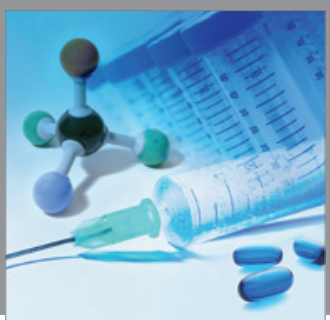

International Journal of

Medicinal Chemistry

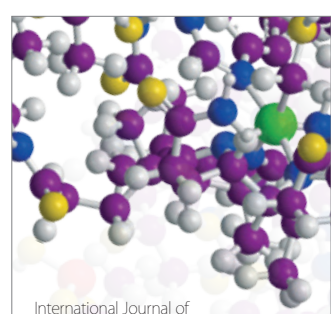

Carbohydrate Chemistry

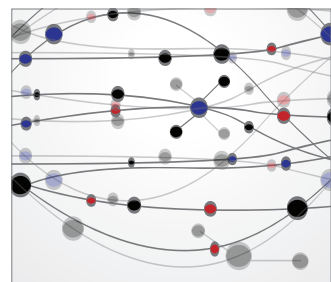

The Scientific World Journal
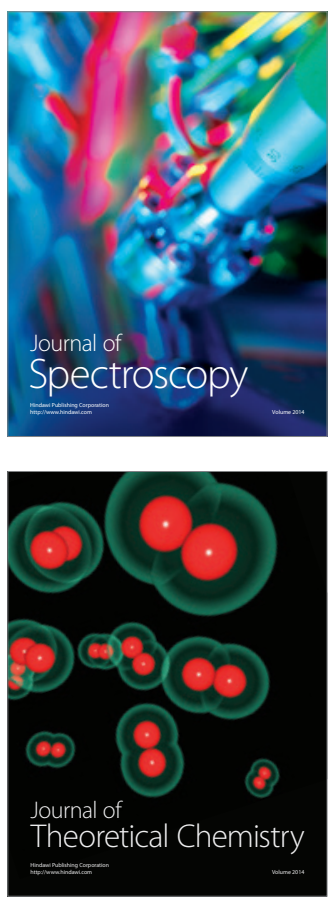
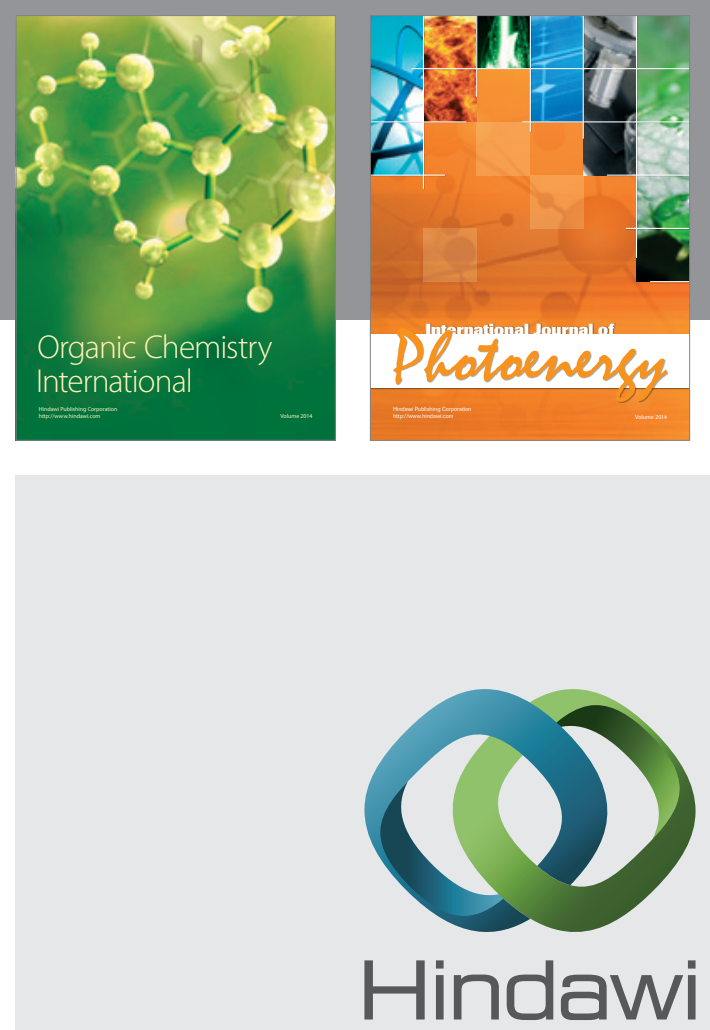

Submit your manuscripts at

http://www.hindawi.com
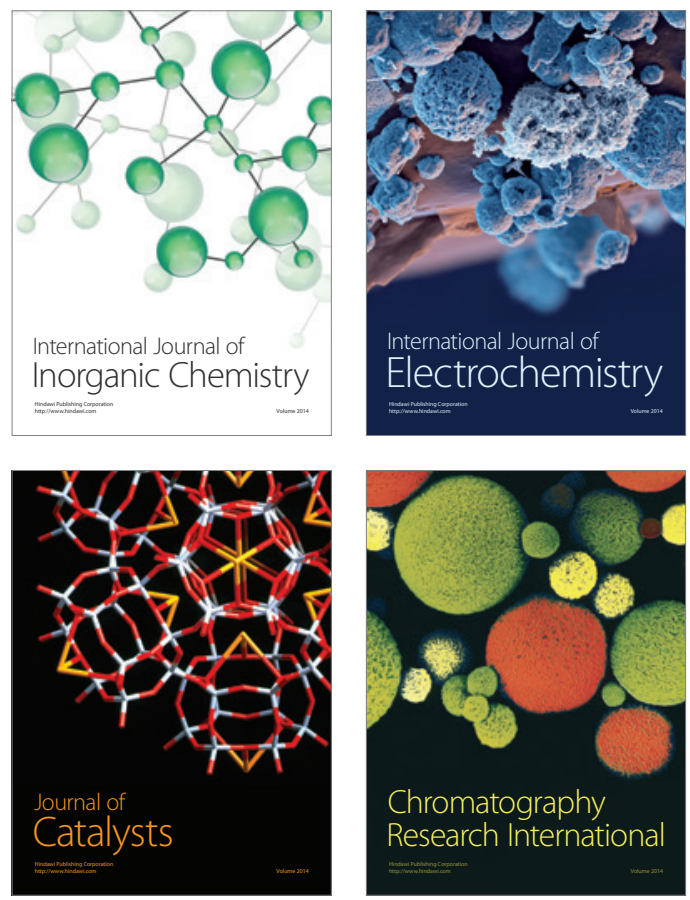
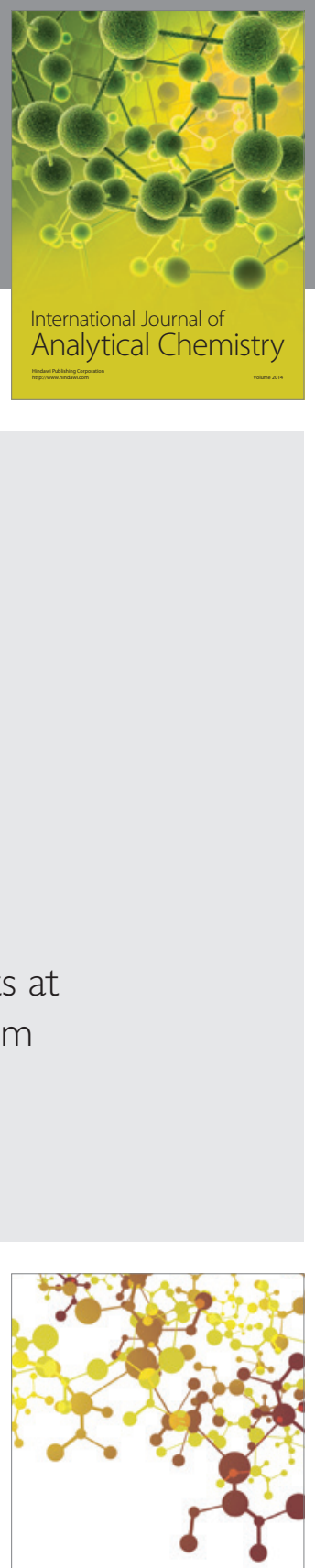

Journal of

Applied Chemistry
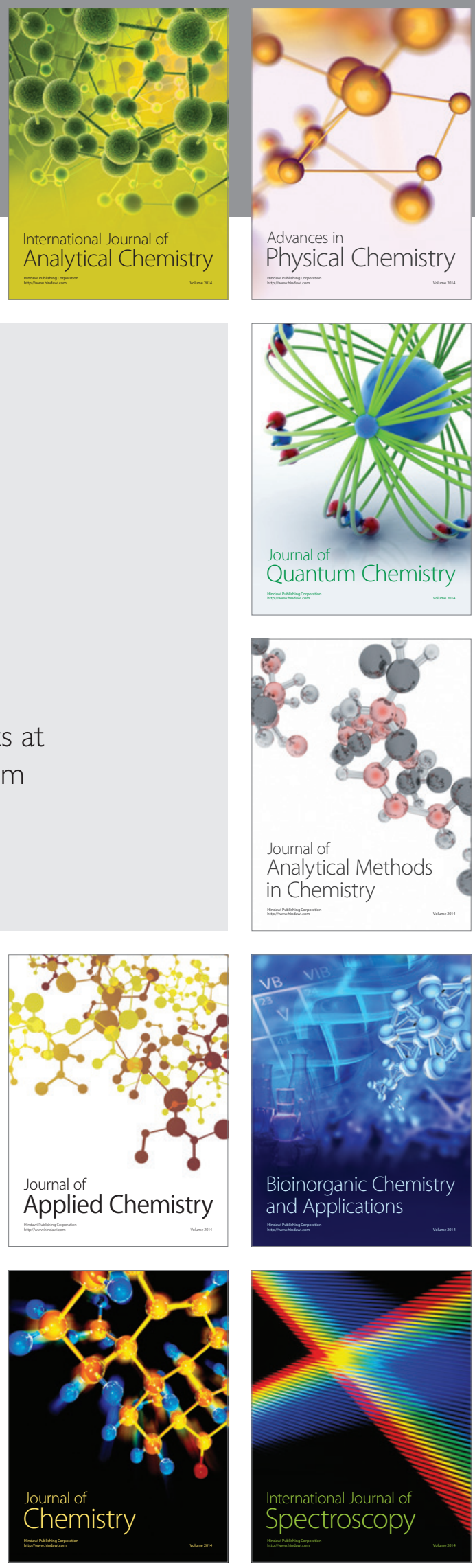